\title{
Sustainable Development Goals (SDG) Target 6.2 in Ethiopia: Challenges and Opportunities
}

\author{
Desale Baye \\ College of Environmental Science and Engineering, UNEP-Tongji Institute of Environment for Sustainable Development, \\ Tongji University, Shanghai, China \\ Email: desalebaye2006@gmail.com
}

How to cite this paper: Baye, D. (2021) Sustainable Development Goals (SDG) Target 6.2 in Ethiopia: Challenges and Opportunities. Open Access Library Journal, 8: e7458. https://doi.org/10.4236/oalib.1107458

Received: April 27, 2021

Accepted: May 15, 2021

Published: May 18, 2021

Copyright () 2021 by author(s) and Open Access Library Inc.

This work is licensed under the Creative Commons Attribution International License (CC BY 4.0).

http://creativecommons.org/licenses/by/4.0/

(c) (i) Open Access

\begin{abstract}
Sanitation is deemed to be a human right. Improved sanitation service access is essential for every community's socio-economic well-being and sustainable development. However, there has been limited research that has evaluated many current sanitation practices across various areas in Ethiopia. Therefore, the purpose of this paper was to assess the Sustainable Development Goals (SDGs) 6.2 in Ethiopia, concerning major challenges and opportunities available towards achieving SDG targets. The data used to evaluate this review was obtained from WHO/UNICEF Joint Monitoring Programme (JMP) report, Ethiopian Demographic Health Survey (EDHS) data, and scientific journal publications stemming mostly from the last decade, to show the research results on water and sanitation, particularly SDGs 6.2 prospects and challenges to provide a general outlook for policymakers in Ethiopia. As a result, this paper analyzed that even though Ethiopia had substantial progress in improving sanitation facilities in the past decades; its coverage is still one of the lowest throughout the globe. Currently, nearly 70 million people (out of about 115 million people) are using unimproved sanitation facilities in Ethiopia. The main reasons for this lowest achievement are as follows: Firstly, sanitation doesn't have a specific organizational "home," implying that roles are disseminated across many sectors. Secondly, the amount of money allocated to the sector is low, and liquid waste disposal facilities are almost non-existent. Thirdly, the sanitation strategy's implementation is not straightforward. Given the existing state of knowledge, the most important strategies needed to tackle the multilateral problem in Ethiopia will be defining specifically identified institutional accountability, capacity building and awareness creation, clear sanitation resource allocation and sustainable sanitation approach concerned with the protection of the environment. The analysis of challenges and opportunities for sanitation services in Ethiopia might be useful for the improvement of SDG 6.2 in other developing countries.
\end{abstract}




\section{Subject Areas}

Environmental Sciences

\section{Keywords}

Sustainable Development Goals, SDG6.2, Sanitation, Wastewater, Ethiopia

\section{Introduction}

Sanitation is deemed to be a basic human right, not just a luxury, to have access to these facilities for every human being. Adequate sanitation is the most significant factor in the field of public health accessible to the global community [1]. Sanitation is the application of different approaches and practices for the safe and sustainable treatment of human excreta, including the collection, storage, treatment, and disposal of human body wastes [2]. It is also characterized as a program encouraging the safe disposal of human and animal waste to enhance and safeguard the natural environment and public health [3]. The Millennium Development Goals (MDGs), introduced in 2000 by the 189 participating countries of the United Nations (UN), included improved sanitation as a priority under MDG 7 (Ensuring environmental sustainability) to halve the number of people with no access to improved sanitation by 2015 [4] [5] [6] [7]. However, the sanitation coverage has not advanced as expected and tends to stay a tremendous task for the next Sustainable Development Goals (SDGs) campaign [8].

Therefore, it is right that sanitation is a key element of the SDGs in the UN that is placed at SDGs 6 . The SDG 6 consists of 8 global targets, of which target \#2 of goal \#6 is especially addressed in this review. This demonstrates a substantial growth in motivation and required significant step-by-step changes in both scales, especially the SDG sanitation goal advocates for sanitation "for everyone" [9]. Access to an advanced sanitation service that the United Nations International Children's Emergency Fund (UNICEF) estimates is not shared within a residential level. The term that we consider in SDG 6.2 was sanitation for everyone without discrimination and differences. Joint Monitoring Programme (JMP) also interprets sustainable sanitation in SDG 6.2 as suggesting a gradual decrease of differences within the community subgroups [10]. Improved sanitation facilities refer to excretion treatment facilities that could effectively prevent contamination from excreta among humans, livestock, and insects. Improved facilities range from easy though secure latrines to flowing toilets with sewerage connections for children [1] [11].

According to the JMP for water and sanitation performed by the World Health Organization/WHO/UNICEF, the percentage of the world's population uses improved sanitation facilities developed by $14 \%$ from $54 \%$ in 1990 to $68 \%$ in 2015 [12] [13]. However, performances were much below the target for 2015 to $77 \%$

[14] [15]. From 2000 to 2017, 2.1 billion people worldwide (26 percent of the 
population) gained access to basic sanitation facilities [16]. Although there has been growth in improved access to sanitation in the developing world, the goal of reducing the population that needs adequate sanitation by 2015 has not been achieved [17]. The sanitation target achievement was not met as planned, particularly in less developed countries and since 1990, globally only $27 \%$ of the populations were offered exposure to adequate sanitation. According to WHO/UNICEF data by JMP in 2015 worldwide 2.4 billion population, even lacked improved sanitation facilities [18] [19] [20] [21] and around 1.8 billion people depend mostly on basic pit latrine [22]. This indicates that over 15 percent of the population around 1 billion people worldwide just don't have access to every kind of sanitation service and that they exercise in open defecation [2] [23] [24]. Approximately 892 million individuals around the world also experienced open defecation, $90 \%$ of those residing in rural areas [25].

Besides, 4.5 billion people throughout the world required a sustainable sanitation service that did not adequately dispose of their excreta in-situ or treated off-site [26]. The dominant number of those people resides in less developed Asian, African, and Latin American regions. The two sub-regions severely impacted the overall population, South Asia with 953 million people and Sub-Saharan Africa, 695 million people demanding adequate sanitation [15] [27] [28]. The existing condition in Africa is highly worrying since just $28 \%$ of its inhabitants in sub-Saharan Africa have received access to adequate sanitation and $23 \%$ of the inhabitants still exercise open defecation [29] [30]. According to the latest JMP report [14], $57 \%$ of the population in Ethiopia had offered proximity to clean drinking water has increased and sanitation services improved by 25\% between from 1990 to 2015 and have remarkable achievement in open defecation which has decreased by $63 \%$ in the same period. In recent years, latrine coverage in Ethiopia has risen to 63 percent.

According to the latest studies available, access to affordable drinking water and sanitation developments in Ethiopia are below the Sub-Saharan and World standards [31]. As a result, it is reported that about $37 \%$ of the people, 45 percent in rural communities, and 16 percent in urban areas (more than 35 million people) actually have no access to every kind of toilet and hence exercise open defecation [2] [32]. The "improved" sanitation levels do not portray any quantity of human body waste which does not safely isolate, conveyed, or handled. A survey of 12 towns across low- and middle-income countries showed that although $98 \%$ of residences provided toilets, only $29 \%$ of human body waste (feces and urine) was safely handled and managed [30]. The handling of liquid waste at the household stage is extremely bad. The plan for the sewer line is not as common to the nation except for Addis Ababa.

Waste handling and treatment services remain neither sufficient nor adequate in Ethiopia, particularly in urban areas. In Ethiopia, poor sanitation remains the biggest development challenge affecting the growth of the country in terms of health, education, gender equality, and socioeconomic development worldwide 
[33]. The potential leadership concerns and enforcement of administering institutions in the sector are indeed the biggest problems in the implementation of appropriate nationwide initiatives. Poor community sanitation practices along with issues such as lack of national policies and sanitation regulators, poor financing for sanitation infrastructure, government monitoring, and evaluation gaps remain the significant challenges facing this low coverage and people, particularly rural communities, urban slums, and other vulnerable groups, are suffering.

However, there has been limited research that has evaluated the current SDG 6.2 in Ethiopia, particularly the major challenges and prospects across various areas. Those studies were more related to inequalities in rural and urban areas and it is indeed uncertain if improvements have been distributed evenly through the population. As a result, it's critical to evaluate sanitation coverage inequalities among rural and urban households, as well as the challenges and potentials that lead to having low progress of SDG 6.2 in Ethiopia. So, analyzing the current major challenges and potentials of SDG 6.2 in Ethiopia allows policymakers and responsible bodies to provide possible solutions for better achievement. Therefore, the main purpose of this research is to analyze the SDG 6.2 in Ethiopia, concerning major challenges and obstacles, and opportunities available for the sanitation sector towards achieving the SDG target. The review was guided by using Ethiopia Demographic Health Survey (EDHS) and WHO/UNICEF JMP data in different years, as well as other related literature.

\section{Current Status and Trends of Sanitation Coverage in Ethiopia}

\subsection{General Introduction to Ethiopia}

Ethiopia, formally the Federal Democratic Republic of Ethiopia (FDRE), is a landlocked nation located in East Africa and never colonized on the continent of Africa. It is located at $8.626703^{\circ} \mathrm{N}, 39.637554^{\circ} \mathrm{E}$ and bordered by at north Eritrea, at east, Djibouti, and Somalia, in western Sudan and South Sudan at south also Kenya. It has an overall land area of 1.13 million. $\mathrm{km}^{2}$. It is the $12^{\text {th }}$ world's populous nation and the $2^{\text {nd }}$ in Africa, with a total population of $112,078,730$ at a population growth rate of $2.6 \%$ in 2019 . Ethiopia's current urbanization is $21.2 \%$ and its urbanization growth rate is around $4.63 \%$ yearly [34] [35]. The mean minimum temperature is $6^{\circ} \mathrm{C}$, while the maximum mean has been rarely above $29^{\circ} \mathrm{C}$. Ethiopia, with an estimated Gross Domestic Product (GDP) of $\$ 81$ billion in 2017, has the GDP per capita recorded at 862 US dollars in the same period [36]. Ethiopia is a place of origin (Arabica coffee origin, home to the Blue Nile, rare species origin... etc.). Ethiopia is blessed with ample capacity for water supplies, known as Northeastern Africa's “water tower.” Ethiopia has 12 major river basins, 12 large lakes, and some man-made reservoirs. The total annual mean discharge from all the 12 river basins is expected to be around 124 billion $\cdot \mathrm{m}^{3}$ and 40 billion $\cdot \mathrm{m}^{3}$ of groundwater [37]. According to Figure 1, Ethiopia, which has 

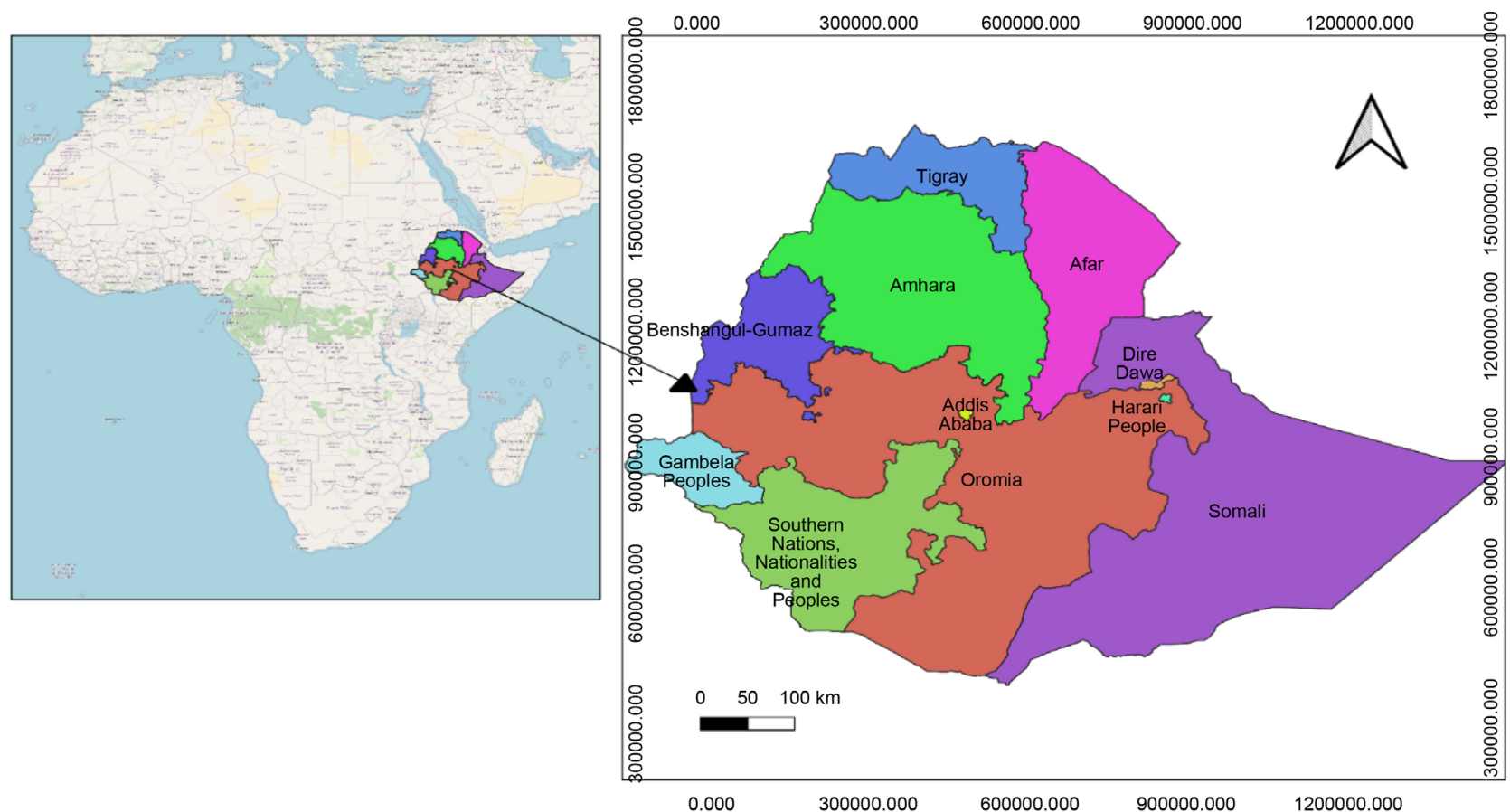

Figure 1. Map of Ethiopia that shows its political-administrative regions, and cities.

nine rural, political, administrative regions based on ethnic territoriality, named Tigray, Afar, Amhara, Oromia, Southern Nations, Nationalities and Peoples' (SNNP), Benishangul-Gumuz, Gambela, Harari and Somali, and two administrative states cities, called Addis Ababa city administration and Dire Dewa city council.

Regarding the introduction in September 2015 of the Sustainable Development Framework 2030 and the SDGs, Ethiopia proactively incorporated and mainstreamed the SDGs with the national strategy. Ethiopia has adopted and supported the sustainable development agenda for 2030 with national responsibilities and ownership to incorporate its SDGs as part of its national development system [38]. The government of Ethiopia acknowledges that improving access to drinking water, sanitation and hygiene is critical for achieving SDGs. Ethiopia incorporated SDG 6 in its $2^{\text {nd }}$ Growth and Transformation Plan (GTP II), the 2015/16 to 2029/30 long-term strategic implementation roadmap. Besides, the Ethiopian government is officially formulating a 10-year prospective development plan for the duration $2019 / 20$ to $2029 / 30$ which is completely compatible with the 2030 framework and SDGs [39].

Accordingly, the adoption of SDGs in Ethiopia has made substantial progress, with a clear understanding of state ownership. Ethiopia has an index score of 53.2 SDG with nearly similar to a sub-regional average score of 53.8 and a global rank of 135 out of 162 SDG countries [9] [31] [40]. Ethiopia has experienced an extremely poor improvement in water and sanitation and has also seen a troubling pattern in the achievements of the past year. Therefore, the current situation of Ethiopia in terms of SDG 6 can be recognized as extremely poor performance 
that most of the people are faced with severe challenges. This requires significant improvement and also this weak achievement indicated a major challenge remains and is not on the track to meet the SDGs at the end of 2030. In the SDG Dashboard, the colors are defined to represent the different levels of the current state and trend.

According to Table 1, Ethiopia has a total score of 41.1 in SDG 6 with a red color rating of major challenges and a very high stagnant tendency to achieve the goal [31]. The arrow in yellow indicates that the SDG 6 pattern in Ethiopia is stagnating, significant challenges remain and it seems hard to meet the target by the end of 2030. Furthermore, the sub-goals are at lower performance and in different situations. Firstly, SDG 6.1, known as population using at least basic drinking water services, is in the situation where major challenges remain and stagnating, and also the trend shows not to be on track to achieve the goal by 2030. Secondly, SDG 6.2, named as population using at least basic sanitation services, is in a situation with major challenges and its trend is daunting and it is difficult to attain the goal [40]. Thirdly, the value of SDG 6.3 shows that the freshwater withdrawal is currently green and in a good situation. The fourth sub-goal (imported groundwater depletion) is in green, indicating that it is on track to meet the target by 2030. Last but not least, SDG 6.5 reveals Ethiopia's treated wastewater is quite insignificant and almost near to zero.

\subsection{Sanitation Status and Trends}

The estimated coverage of Ethiopia sanitation facility indicated as improved, shared and other unimproved facilities have reached $28 \%, 14 \%$, and $29 \%$ in 2015 compared to $3 \%, 14 \%$, and $1 \%$ respectively in 1990 .

According to Figure 2, Ethiopia has an improved sanitation facility of around $8.6 \%$ in 2000 and it has $28 \%$ achievement in 2015 that increased by 20 percent within 15 -year intervals [14]. Only $7 \%$ of the population ( $0.63 \%$ rural, $18 \%$ urban) used basic sanitation facilities, and $6.84 \%$ of the population (1.26\% rural,

Table 1. SDG 6 Water, Sanitation, and Hygiene (WASH) achievement of Ethiopia [31] [40].

\begin{tabular}{|c|c|c|c|c|c|}
\hline & SDG 6 & Values & Rating & Trend & Remark \\
\hline \multirow[t]{2}{*}{ General goal } & Clean water and sanitation & 41.1 & & $\Rightarrow$ & $\begin{array}{l}\text { Stagnating } \\
\text { trend }\end{array}$ \\
\hline & $\begin{array}{l}\text { Population using at least } \\
\text { basic drinking water } \\
\text { service }(\%)\end{array}$ & 39.1 & & $\Rightarrow$ & Stagnating \\
\hline \multirow{4}{*}{$\begin{array}{l}\text { Sub-goals } \\
\text { (Targets) }\end{array}$} & $\begin{array}{l}\text { Population using at least } \\
\text { basic sanitation service (\%) }\end{array}$ & 7.1 & & & Stagnating \\
\hline & Freshwater withdrawal (\%) & 11.6 & & & \\
\hline & $\begin{array}{l}\text { Imported groundwater } \\
\text { depletion ( } \mathrm{m}^{3} / \text { year/capita) }\end{array}$ & 1.3 & & & \\
\hline & Wastewater treated (\%) & 0.0 & & & \\
\hline
\end{tabular}




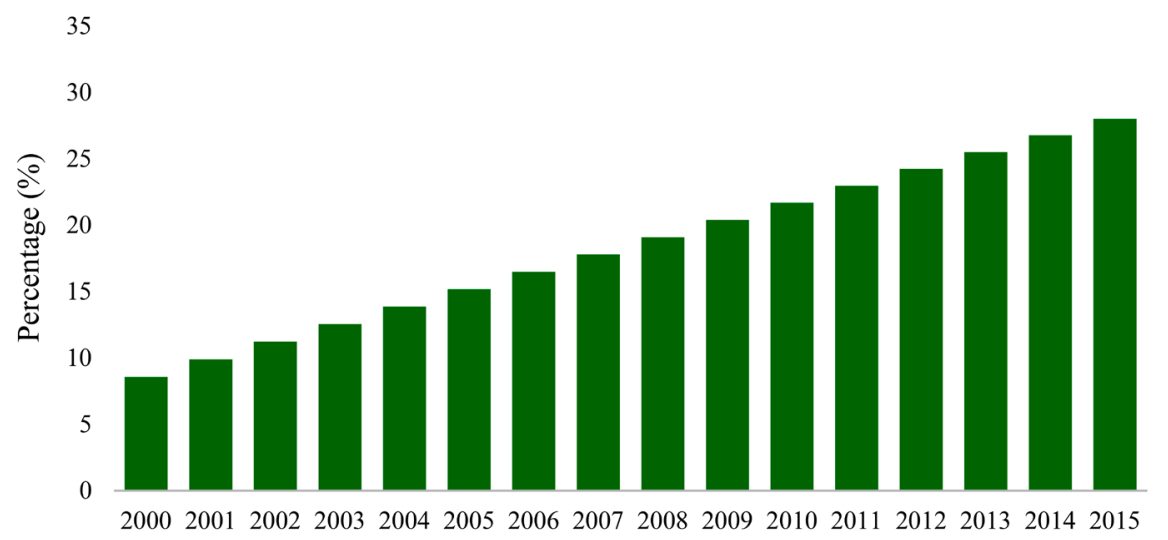

Figure 2. The proportion of the population using improved sanitation facilities in Ethiopia, 2000-2015 [14] [23] [41] [42] [43].

$30 \%$ urban), used limited sanitation facilities and $59 \%$ of the population $(62.4 \%$ rural and $44 \%$ urban) used unimproved sanitation facilities. This indicates that around 72 percent of people in Ethiopia live without adequate sanitation facilities [8]. In 1990, 44.3 million people experienced open defecation and 28.3 million in 2015, indicating a higher decrease over the 25 years [14].

Reporting the data and making it available is very important. However, there are some nationwide studies in Ethiopia on access to household sanitation, such as reports from the DHS in Ethiopia and WHO/UNICEF JMP. There are no reliable structured sanitation data available after 2015 and this is also a major problem to evaluate the existing situation in Ethiopia. Estimation and correlation of statistics from the countrywide survey of sanitation facilities show $47.9 \%$ have access to improved sanitation facilities and $52.1 \%$ of the population in Ethiopia is facing unimproved sanitation facilities [14] [44]. It can be recognized that the EDHS survey is the only monitoring tool in Ethiopia to identify and collect data on shared latrines [32].

According to Figure 3, the number of households with open defecation has decreased from 82 percent in 2000 to 32 percent in 2016. Reducing the proportion of people practicing open defecation in Ethiopia has been a great achievement in these periods, representing a reduction of 50 percent within fifteen years. The result also showed a slight $1.2 \%$ increase from 2000 to $2005,1.4 \%$ from 2005 to 2011 , and the use of improved sanitation was decreased by $2.8 \%$ in 2011 and 2016. There was a higher reduction recorded in 2016, only $15 \%$ of households used improved sanitation. In rural areas, a decline was detected in the percentage of households using improved sanitation. A household survey of 16 cities and political regions in Ethiopia, which examines data based on JMP concepts, reveals that $57 \%$ of households have access to improved sanitation, $25 \%$ unimproved sanitation, and $13 \%$ of households suffer from open defecation. A minimal proportion (4 percent) of households uses services shared with other residences [49].

According to Figure 4, open defecation was $77 \%$ in 2000 and is reported as having reduced from $92 \%$ in 1990 to $29 \%$ by 2015 as well as it has decreased by 


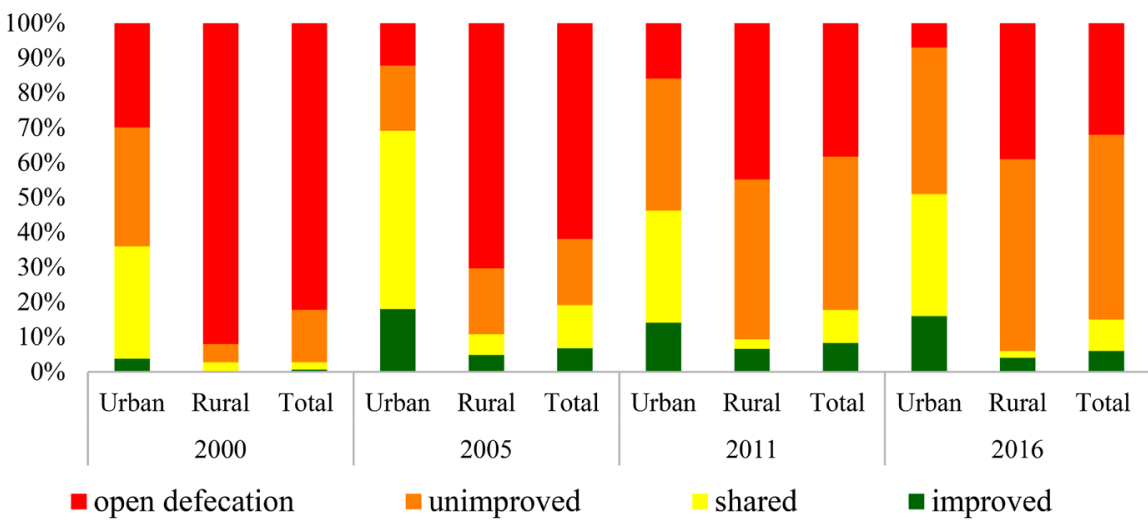

Figure 3. Percentage of the population access to sanitation facilities in Ethiopia [45] [46] [47] [48].

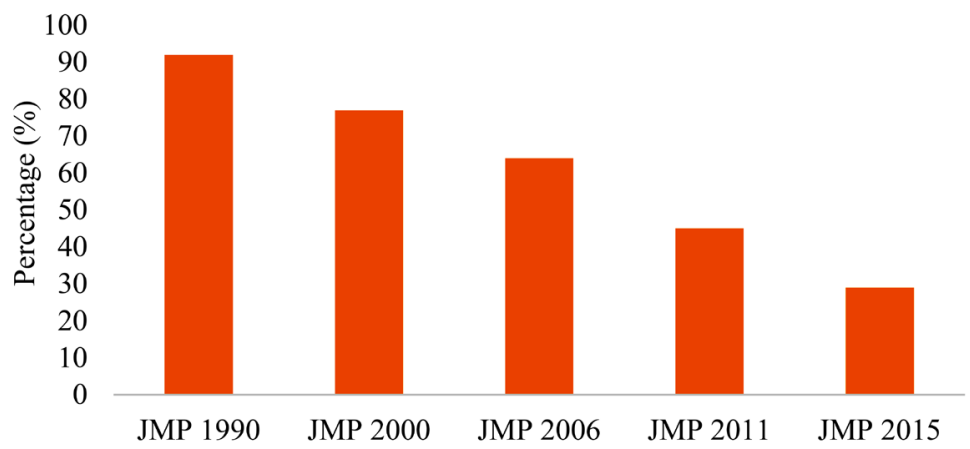

Figure 4. Percentage of a population exercising open defecation by JMP (Joint Monitoring Programme) [14] [23] [41] [42] [43].

almost $63 \%$ in 25 -year. There was a 4.7 percentage level improvement in urban residences using improved sanitation in the years 2011 and 2016, while the proportion of rural residences using improved sanitation was reduced by 3.4 percentage points. $85 \%$ of the nation used unimproved sanitation in $2016,94 \%$ of which were in rural areas and $49 \%$ were urban. The urban/rural study revealed a substantially greater percentage of open defecation in rural areas. Although the findings resulted in a decrease of 8.9 percentage points from 2011 and 2016, and also a lower incidence of open defecation in urban areas in general, the percentage of open defecation residences enhanced by 12.2 percent in 2005 and 15.9 percent in 2011. It has already been established that one of the greatest challenges highlighted in SDG enables everyone to have access to adequate and equitable sanitation and hygiene, as well as avoiding open defecation, giving particular consideration to the demands of women and girls and others within marginalized circumstances [43]. However, achieving this admirable goal is not feasible without a much greater emphasis on geography and community disparities in access to sanitation, along with rural and urban communities, poor and rich, men and women, or marginalized communities compared to the total population [50].

In reality, the disparity can be interpreted simultaneously in four meanings, specifically, spatial disparities, demographic disparities, gender disparities, and 
intergenerational disparities [51]. Sanitation facilities and coverage also have disparities between urban and rural areas globally, including Ethiopia [52]. According to WHO/UNICEF, the improved sanitation facility in 2015 was $27 \%$ in urban areas and $8 \%$ in rural areas, whereas the peoples who practiced open defecation were $6 \%$ in urban areas and $34 \%$ in rural areas. According to EDHS [48], the improved sanitation facility in 2016 was $15.9 \%$ in urban and $3.9 \%$ in rural areas, whereas the peoples practicing open defecation were $6.9 \%$ in urban and $38.8 \%$ in rural areas. This indicates that the sanitation coverage in rural areas much lower than in urban areas and $81 \%$ of the population of Ethiopia is also living in rural areas. Besides, approximately 92 percent (nearly 73.6 million people) of the population live without improved sanitation. In comparison, $34 \%$ of the rural population has practiced open defecation [14].

Several types of researches have made the point that urban areas have more toilet access relative to rural areas [51]. Furthermore, there are also disparities between administrative regions [54]. Based on the survey conducted in 2016 in rural, political, administrative regions of Ethiopia indicated that five regions have better performance varying from 51\% in Amhara to 91\% in Benishangul Gumuz. There are, however, three areas Gambella, Afar, and Somali-where open defecation still takes precedence, downplaying the national average. The EDHS 2016 report also indicated the same result. Figure 5 above also shows in the region Afar, Somali and Gambella open defecation is $70 \%$ on average and still predominant that brings down the result showed the national average [53]. The national study conducted in Ethiopia also showed the emerging regions such as Afar, Somali, Benishangul Gumuz, and Oromia's pastoralist areas face unique health service delivery challenges sanitation in particular [55].

Ethiopia's pastoralist segment, the arid and semi-arid regions covering 61 percent of the national base and occupying 12 - 15 percent of the total population of the country, is residence to millions of pastoralists among various ethnic groups. Research has shown that pastoralists also long been excluded from the central government, and were among the most disadvantaged in terms of affordability

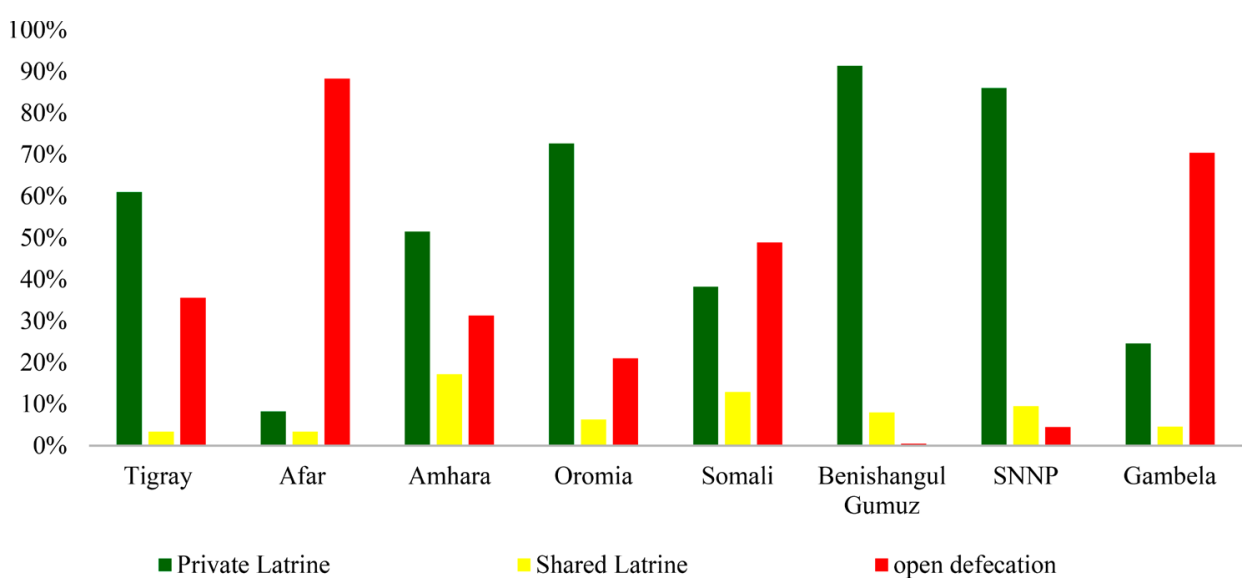

Figure 5. Percentage of the population access to the latrine in rural political administrative regions of Ethiopia [53]. 
and connection to sanitation facilities. It has a low sanitation facility due to the nature of the area characterized by poor water supply, mobile lifestyle of the community, soil property, lack of qualified manpower, and habit of open defecation. There was also a disparity of sanitation facilities based on wealth. As worldwide figures suggest, people without links to basic sanitation in Ethiopia are those in lower per capita income groups, with more than three-quarters of the lowest income group exercising open defecation equal to merely 12 percent of the richest.

The absence of access to improved sanitation and open defecation practices has a substantial socio-economic effect on homes without access, including those belonging to families with low access to sanitation [32] [56]. While urban sanitation is usually bigger than rural access, the small, unplanned, densely populated areas are generally considered to be severely unwarranted. Dry pit latrines composed of simple and improved pit latrines used by 92.5 percent of the people of Ethiopia demand frequent maintenance, especially pit emptying and better handling of fecal sludge [57]. There was no adequate care for and valorization of fecal sludge in Ethiopia. Consequently, if the chain Fecal Sludge Management (FSM) system were used as a control criterion, none of Ethiopia's sanitation facilities would count as adequate sanitation services. Response to better sanitation within the framework of the SDG should also be regarded as appropriate management and valorization of fecal sludge as response measures that increase sanitation coverage [44]. Most latrines store liquid waste using septic tanks, latrine pits (seepages), and cesspools. Either city vacuum vehicles have been used once these storages are loaded, or the capacity is emptied freely or into sewer systems such as community culverts. Research in Bahir Dar city, Northern Ethiopia, for example, revealed that $64 \%$ of residences spill liquid waste into the nearby public area [58].

\subsection{Wastewater Treatment}

Particularly, to achieve SDG 6.2, attention has been given to the collection, transport, and handling of human body waste and wastewater, as well as hygiene. Sanitation solutions are typically categorized as distributed (cluster network and on-site systems) or decentralized. The more expensive the centralized system consists of a wastewater network with various pipe sizes needed to transport wastewater from a significant number of households' central wastewater treatment plants, apart mainly from wastewater sources [12]. The government of Ethiopia currently uses conventional decentralized sewage treatment systems in many areas of the state. Wastewater is harvested, treated in decentralized systems and the sewage is recycled or discharged from anywhere around the manufacturing source [59]. The best kind of decentralization is the on-site facility located at the source of wastewater generation; this involves no sewer line network. Household owners are left to operate and manage on-site disposal systems, which created challenges as many currently in use conventional systems do not provide treat- 
ment. At the moment Ethiopia is subjected to the deterioration of the water resources connected with wastewater and the bad management of solid waste, sludge, and sewage [60]. Nearly all segments of rural Ethiopia are non-sewer areas. Sewage connections are rare in Ethiopia even in urban areas $(0.4 \%-6.6 \%)$ and nonexistent in rural areas. The urban and peri-urban parts of Ethiopia are characterized by inadequate sanitation, indiscriminate waste disposal, and open defecation. The United Nations Environment Programme (UNEP) reports that $90 \%$ of the less developed world does not handle and manage wastewater until it is discharged freely into the environment [61] [62]. Globally, approximately 1.5 billion people have access to sanitation facilities that do not handle excreta in the environment until it is discharged [63].

The national survey in Ethiopian cities showed that the characteristics of household liquid waste disposal facilities with sewer lines were only $7 \%$. For instance, Addis Ababa, the capital city, produces nearly 49 million $\cdot \mathrm{m}^{3}$ of total wastewater per annum where about 4 million $\cdot \mathrm{m}^{3}$ of industrial wastewater is produced. It has two secondary wastewater treatment plants (kality with a potential of approximately $7600 \mathrm{~m}^{3} /$ day or $228,000 \mathrm{~m}^{3} /$ month and Kotebe-sludge treatment capacity-of $85,000 \mathrm{~m}^{3} /$ year) and a centralized sewerage system/sewer line with an average treated wastewater of less than $10 \%$ or $7.03 \%$ in 2017 and it is connected to the sewer line [64] [65]. As a possible consequence, wastewater treatment plants release wastewater freely into the ecosystem, slightly or entirely untreated [61]. Effluent from water and sewage and pit latrines and urban waste, trigger algae and weed production, which decreases the water body's oxygen levels, which in turn influences the marine and vegetation ecosystems. Sewage from domestic households, underground storage and tube leakages, wastewater, and septic tanks are considered to be the major causes of water pollution. This allowed sewage and wastewater directly discharged to water bodies that pollute the water source that affects people and the environment as a whole. It is largely due to the absence of policy and strategy on the sustainable utilization of wastewater, inadequate implementation of pollution prevention and control systems, lack of awareness of waste management, and high investment costs needed for treatment plants.

\section{Challenges in Achieving SDG Sanitation Targets in Ethiopia}

Even though Ethiopia has made substantial progress towards sanitation coverage just $29 \%$ of the population, close to 30 million inhabitants don't have access to adequate sanitation. Thirty-four percent (34\%) of rural inhabitants approach open defecation, relative to $6 \%$ of urban dwellers. Sewerage connections are uncommon in urban areas $(0.4 \%-6.6 \%)$ and non-existence for rural areas [66]. The increasing problems with environmental sanitation and sewage treatment in Ethiopia can be considered as a consequence of the lack of institutional homes, which implies that duties are shared between several authorities, and lack of clear im- 
plementation approach of the sanitation strategy, the sector is underfunded, and the shortage of treatment facilities for liquid waste remains a major problem for the country to have poor sanitation coverage [67].

\subsection{Policy and Institutional Challenges}

The slow improvement in exposure to adequate sanitation in Ethiopia and several less-developed nations also may be related to a limitation of interpreting approaches, policies, and practices; flawed sector-specific integration; and inadequate national budget allocations [44]. In many governments, operations are the responsibility of governments, such as policy formulation, creation of regulatory structures, planning, coordination, financing and funding, capacity building, data collection and monitoring, and regulation [26] [68]. The development of environmental health practices in Ethiopia does indeed have a strong tradition from the 1900s [69]. As shown below in Table 2 since the 1993s, the sanitation and hygiene sector in Ethiopia has undertaken many initiatives through the development of appropriate institutions, regulatory and legal structures to resolve sector constraints [70] [71] [72]. In 2010, according to the UN Economic

Table 2. Policy and institutions implemented in sanitation and hygiene target.

\begin{tabular}{|c|c|c|}
\hline Year & Type of policy & Major tasks and provisions \\
\hline $1900-1993$ & $\begin{array}{l}\text { Public health Services and } \\
\text { Ethiopian national health } \\
\text { Policy }\end{array}$ & $\begin{array}{l}\text { Sanitation standards and small-scale drinking } \\
\text { water system constructions and latrines in rural } \\
\text { areas }\end{array}$ \\
\hline 2001 & $\begin{array}{l}\text { Water supply and sanitation } \\
\text { policy }\end{array}$ & Implement and treat the waste \\
\hline 2002 & Environmental policy & Environmental pollution control \\
\hline 2004 & $\begin{array}{l}\text { The health extension program } \\
\text { was started }\end{array}$ & $\begin{array}{l}\text { Mandate major activities to encourage } \\
\text { sanitation and hygiene and establish a } \\
\text { monitoring and evaluation system, as well } \\
\text { as the execution of a countrywide water supply, } \\
\text { sanitation, and hygiene. }\end{array}$ \\
\hline 2005 & $\begin{array}{l}\text { Developed the national } \\
\text { on-site sanitation strategy, } \\
\text { signed the national } \\
\text { memorandum of } \\
\text { understanding, initiated the } \\
\text { national WASH campaign, } \\
\text { and employed health } \\
\text { extension staff. }\end{array}$ & $\begin{array}{l}\text { It puts forward three strategic pillars for } \\
\text { improved sanitation and hygiene: creating an } \\
\text { enabling environment, sanitation, and hygiene } \\
\text { promotion, and improved access to hardware. }\end{array}$ \\
\hline 2006 & $\begin{array}{l}\text { National hygiene and on-site } \\
\text { sanitation protocol developed }\end{array}$ & $\begin{array}{l}\text { Progress made in improving Sanitation \& Health } \\
\text { and implementation and future directions. }\end{array}$ \\
\hline 2013 & Waste management policy & $\begin{array}{l}\text { The proclamation confers on waste } \\
\text { management or sanitation. }\end{array}$ \\
\hline 2011-2015 & $\begin{array}{l}\text { National sanitation and } \\
\text { hygiene strategic action plan }\end{array}$ & $\begin{array}{l}\text { The strategy primarily focuses on hygiene and } \\
\text { sanitation that is implemented for the wastes } \\
\text { handling mechanism. }\end{array}$ \\
\hline
\end{tabular}


and Social Council Declaration on the right to sanitation: States must guarantee that all have adequate as well as sufficient access to improved sanitation across most fields of society which are clean, hygienic, socially, and culturally appropriate, provides confidentiality and guarantees dignity [68].

Although this demonstrates significant advances, most of these improvements stay insufficient as well as a majority of persistent obstacles have to be addressed to develop the organizational capacity to achieve and maintain levels of MDG and SDG coverage. Quite significantly, these include ongoing chronic monitoring and evaluation constraints that make the sector doubt one's improvements as well as the feasibility of strategies and restrict prospects for advanced education [73]. Monitoring variations in sanitation and hygiene coverage remains a significant challenge the country is facing [74] [75]. The $\mathrm{MoH}$ is responsible for monitoring health and hygiene activities in Ethiopia, but the prevailing trend in recent years has always been to coordinate planning, monitoring, and reporting within the WASH sector. To this end, their cooperation and coordination have been improved by the $\mathrm{MoH}, \mathrm{MoWE}$, the Ministry of Education (MoE), and the Ministry of Finance and Economic Development (MoFED) [32]. Low levels of financial utilization of funding sources resulting from insufficient coordination as well as integration with fundamental government structures and significant potential human capital difficulties, particularly at (i.e., District) level, despite major, but separate capacity-building projects under the framework [73].

Governments and enterprises, as well as health ministries, in particular, could never achieve their prominent roles as sanitation coordinators and regulators without policy initiatives that encourage the development of government institutions into the leading health institutions, focusing specifically on domestic activities and public participation, promoting competition and integrating sanitation and hygiene in health systems [76]. Today, on a national level, government budgets for health services are higher than most, and expenses for health services have increased much faster than most other sectors. Nevertheless, in previous years, the lack of national policies has been a significant problem in battling sanitation problems [56]. Mainstreaming sanitation issues in various public and non-governmental organizations, given the presence of their nomenclature and structure, is still an incomplete mission. The political branches of governments cannot perform their essential functions as sanitation watchdogs. Experts and managers of health and the environment are the people responsible for persuading society and other stakeholders. The society's socioeconomic and knowledge level is limited in general at the national level, and particularly in rural sections.

\subsection{Water Scarcity}

Over the last few decades, it has become clear that the growing demand, the sustainable growth of human society, and the worldwide systemic hazard of freshwater scarcity are increasingly being seen as a challenge due to a freshwater 
shortage. Water scarcity impacts above $40 \%$ of the global population and that number is expected to increase. At present, 4 billion people are estimated to be living under devastating water scarcity for about one month of the year, and 500 million of them face extreme water scarcity across the year [77]. Water scarcity is expected to increase in many areas of the developing nations like Ethiopia and will have an effect on progress towards the achievement of SDG \#6.2, as there might be inadequate or only sub-optimal quantities of water for handwashing menstrual hygiene control, food hygiene, low-volume latrine pour-flushing, and even hydraulic condominium sewerage service, as well as personal cleanliness. Even if Ethiopia has a plentiful amount of water resources, the available water is not distributed evenly across different areas of the country and the amount varies with seasons and years. Besides, to meet their regular water needs for both drinking and sanitation, the people of Ethiopia still have a long way to go, especially in the rural regions of Ethiopia.

\subsection{Lack of Finance and Level of Poverty}

There is a very strong need for additional financial support to meet the SDG 6.2 goal and the investment requirements in the sanitation sector rise significantly [78]. Time and money will be heavily invested in designing and constructing new infrastructure. More financing is required, from more productive use of existing capital to new funding standards to stronger prospects for a dramatic change in the coming years [79]. Official Development Assistance (ODA) disbursements for the total water sector rose between US $\$ 7.2$ billion during 2011 to US $\$ 8.8$ billion globally by 2016 [26]. Currently available financial resources for implementing SDG 6 are insufficient. The World Bank projected as US $\$ 114$ billion a year the total investment costs of achieving SDG goals 6.1 and 6.2. This does not include any other goals for SDG 6 and also this ignores operation and repair, supervision, institutional support, sector enhancement, and human resources. The overwhelming challenge is to plan, develop, and maintain systems for water, wastewater, and sanitation to promote universal access to clean water and sanitation [80]. The funding needed to improve the enabling environment is insufficient to deliver improved sanitation services for households.

Ethiopia is spending $0.01 \%$ of its GDP on sanitation. The MoWE is budgeting about US $\$ 18$ million annually for the reconstruction and extension of the Addis Ababa sewerage network. In 2007, an evaluation of institutional sanitation requirements projected the expense of sanitation to current schools and health facilities to be an estimated US $\$ 510$ million. Total spending costs for sanitation equipment are projected at US\$795 million annually due to the low current level of coverage, all of which households are required to contribute. A rough estimate of planned public investment in sanitation puts the overall projected investment in sanitation at about US\$50 million each year [73]. The funding deficit in Ethiopia is currently estimated at 60 - 70 percent of the SDG requirement. Universal improved sanitation and open defecation free may be met by 2030 given that fi- 
nancing investment can increase from the current less than 1\% of GDP to 2 to $4 \%$. Furthermore, there is not only a lack of finance in the region, but also unexploited use of repayable finance, such as microfinance and mixed-finance, and insufficient distribution of financial resources to the poor and disadvantaged who cannot access facilities.

\subsection{Population Growth and Density}

The decline in access to improve sanitation in Ethiopia is mainly a function of rapid population increase. The expected accelerated population growth in less developed regions is among the main challenges in achieving the target of safe-accessible sanitation for everyone in 2030. The urban population is projected to be about 4 billion in low- and middle-income countries, whereas the rural population is estimated to be approximately 3 billion by 2030 [1]. The urban population in Africa with no upgraded sanitation facilities rose from 80 million in 1990 to 215 million in 2015 due to population growth. The major challenges in the provision of sanitation services also involve rapid urbanization [81]. In most sub-Saharan African country's infrastructure is lacking as regards sewer systems, and sewer networks are minimal. For example, in Ethiopia, the Kality treatment plant, established in 1983, initially planned to supply 50,000 residents of Addis Ababa, but it's only serving 13,000 people over 30 years. Moreover, several infrastructure solutions, including building wastewater treatment plants, disintegrate or fail to adequately meet the sanitation requirements [82]. As shown below in Table 3 Ethiopia's population without enhanced sanitation facilities increased from nearly 46.6 million in 1990 to almost 70.2 million in 2015. This is the result of the increment of population growth from 48 million in 1990 and 98 million in 2015 with a 50 million total population increment within 25 years. So, this requires serious attention to improve the population that is living with unimproved sanitation facilities take into consideration population growth [14].

Table 3. Total population with access to sanitation facilities in Ethiopia by JMP (Joint Monitoring Programme) [14] [23] [41] [42] [43].

\begin{tabular}{|c|c|c|c|c|c|}
\hline \multirow{2}{*}{$\begin{array}{c}\begin{array}{c}\text { Evaluation } \\
\text { years }\end{array} \\
\\
\text { JMP } 1990\end{array}$} & \multirow{2}{*}{$\begin{array}{c}\text { Total } \\
\text { population }\end{array}$} & \multirow{2}{*}{$\begin{array}{c}\text { Population } \\
\text { with access } \\
\text { to improved } \\
\text { sanitation } \\
\text { facility } \\
1,441,290\end{array}$} & \multirow{2}{*}{$\begin{array}{c}\text { Population } \\
\text { with access to } \\
\text { unimproved } \\
\text { sanitation } \\
\text { facility } \\
46,601,710\end{array}$} & \multicolumn{2}{|c|}{$\begin{array}{c}\text { Total population } \\
\text { increments in } 5 \text { evaluated } \\
\text { years (increment in } \\
\text { population number and \% } \\
\text { of increment i.e., total } \\
\text { population minus JMP } \\
1990 \text { up to } 2015 \text { ) }\end{array}$} \\
\hline & & & & Benchmark & $0 \%$ \\
\hline JMP 2000 & $65,578,000$ & $5,246,240$ & $60,331,760$ & $17,535,000$ & $36.5 \%$ \\
\hline JMP 2006 & $81,021,000$ & $8,912,230$ & $72,108,770$ & $15,443,000$ & $23.5 \%$ \\
\hline JMP 2011 & $84,734,000$ & $17,794,140$ & $66,939,860$ & $3,713,000$ & $4.5 \%$ \\
\hline JMP 2015 & $98,942,000$ & $28,693,180$ & $70,248,820$ & $14,208,000$ & $16.8 \%$ \\
\hline
\end{tabular}




\section{Impacts of Inadequate Sanitation}

\subsection{Health Consequences}

Health consequences safe sanitation collection, transportation, and disposal, waste is still an ignored environmental problem in towns [82]. Lack of sanitation and contaminated water and result in bacteria being spread pathogens and, to a lesser degree, in the urine [76]. Insufficient sanitation and weak hygienic practices result in tremendous public health expenses and diseases [51]. The sanitation problems constitute $10 \%$ of the worldwide disease threat [56] [83]. Improper handling of human body waste poses a significant public health hazard [84]. Many of these diseases are spread through fecal-oral pathways, but others are transmitted via fecal-skin (such as schistosomiasis) and fecal-eye pathways like trachoma [30] [85]. 200 million tons of human wastes go uncollected and untreated worldwide per year [33]. In Ethiopia, $60 \%$ of overall diseases are related to poor sanitation and unsafe water supply [56].

Diarrheal disease: This disease is the world's most severe fecal-oral disease, causing approximately $1.6-2.5$ million fatalities annually, mostly of children under the age of five living throughout less-developed nations [76] [86] [87]. Diarrhea is the second most frequent reason for the death of children below age 5 , with no improvement in the past ten years [88]. Those diseases are identified in the Ethiopian context by poverty and lack of knowledge of basic sanitation [89]. Diarrheal diseases are Ethiopia's first significant diseases, the main cause of death in millions primarily below 5. For example, in 2016 diarrhea was the primary factor for mortality in Ethiopia for infants below five resulting in 10 percent of all deaths [56]. In Ethiopia alone, about 600 children are dying from diarrhea every day [90].

Trachoma: This is the world's number one cause of contagious blindness. Trachoma is accountably causing vision loss for nearly 2.2 million individuals worldwide, from which 1.2 million have become permanently blind [30] [56] [91]. Ethiopia is one of five world countries where half the active trachoma burden is concentrated all over the world. The National Regional State of Amhara (ANRS) is adversely impacted by trachoma among the 9 rural, regional states, and two chartered cities in Ethiopia [91].

Helminth infections and Schistosomiasis: Helminth infections are transmitted in water (schistosomiasis) and soil (soil-transmitted helminths, STH) via fecal matter [30]. Intestinal worms infect around $10 \%$ of the developing world's population, including Ethiopia [76]. They can harm the liver, stomach, lungs, and bladder [56]. Sub-Saharan Africa bears three-quarters of the burden [30] [76]. Schistosomes and STHs are significant public health problems in Ethiopia, with national prevalence recorded at $16.5 \%$ and $28.8 \%$ respectively. On the other hand, over 11 million pre-school children (aged 2 to 5 years) obtained preventive chemotherapy (PC) against STH infections within the years 2004 and 2009 [92].

Undernutrition: It causes approximately $45 \%$ of all infant fatalities and con- 
tributes to $11 \%$ of the world's disease load [30]. Undernutrition, inadequate sanitation, hygiene, and water account for around 50\% of childhood and maternal underweight results, primarily through the interaction between diarrheal and undernutrition [76].

\subsection{Environmental Consequences}

Waste poses a major threat to the human environment and, thus, to health primarily because of how it can be disposed of [93] [94]. Insufficient and unsanitary treatment of contaminated human wastes contributes to the pollution of soil and water supply sources. Human waste management is among the key critical environmental health initiatives that the WHO has identified as one of the key measures to be followed to protect our environment. The current poor water and sanitation coverage in Ethiopia provides a drastically adverse environmental effect. The significant environmental impact of inadequate sanitation practices is contamination from poorly controlled human excreta. The absence of sufficient sanitation is a serious challenge for the ecosystem, destroying the urban environment by indiscriminately discharging solid and liquid waste and polluting freshwater and reservoirs with untreated human waste. Poor sanitation causes sewerage or waste stream inappropriately towards rivers, streams, lakes, and wetlands that threaten coastal and marine environments and subject people to pollution. Poorly managed waste also means being subjected to an unhealthy ecosystem regularly [86]. In addition to this, poorly treated human excreta have significant implications for ecosystem impacts, contaminating human communities and water bodies. A large proportion of wastewater discharged towards rivers, lakes, oceans, and surrounding streams in Ethiopia contaminates some of the same facilities that people use as drinking water. Untreated sewage discharges pollute the environment along with polluting sources of drinking water and affect plant and marine life. Municipal wastewater and sewage account for a huge amount of total biological oxygen demand in densely populated river basins [30].

\subsection{Financial and Economic Consequences}

Although economic and financial analysis shows that sanitation provides economic benefits, the individual investing in improved sanitation doesn't automatically gain from the investment. Therefore, household-level economics is an obstacle to health care development. Besides, many people are unable to spend the cost of inadequate sanitation in East Asia, and the Pacific and sub-Saharan African economies have surpassed 2\% of total GDP, whereas, in South Asia, they have surpassed $4 \%$ of GDP. Poor financing for the sanitation sector and associated organizations inhibited the successful implementation of policy reforms. Costs are particularly significant in achieving the SDG \# 6.2 target of safelymanaged sanitation. Inadequate WASH infrastructure causes a yearly loss of approximately US $\$ 260$ billion in less developed nations [95]. Some countries cost 
billions equal to the equivalent of $7.2 \%$ of GDP in Cambodia, $6.3 \%$ of GDP in Bangladesh, 6.4\% of GDP in India, 3.9\% of GDP in Pakistan, and 2.4\% of GDP in Niger and per annum estimated by World Bank [29] [96]. The annual costs of flood damage, insufficient WASH, and water shortage are estimated at USD 500 billion. It is also reported that low-quality sanitation infrastructure in Ethiopia costs US\$570 million (13.5 billion Birr) annually, which is estimated to be $2.1 \%$ of the national GDP [30].

\subsection{Impact on Well-Being}

The concern for waste disposal has also a social and economic effect on the country. Connection to improved sanitation services is essential to every society's socio-economic health and sustainable growth [3]. Low sanitation decreases human well-being, socio-economic growth related to consequences including sexual harassment, anxiety, risk, and missed opportunities for education. The problem with access to adequate sanitation and the widespread practice of open defecation affects households without access and those living in communities where access to sanitation is poor [32]. Improved sanitation provides individuals with greater comfort, security, dignity, and position; along with wider environmental impacts. Nonetheless, these advantages are widely recognized as among the most significant for sanitation beneficiaries and may be of particular relevance to women [30]. On-plot sanitation decreases any threat of theft or violence (including sexual assault and rape), particularly during the night or in remote areas.

\section{Opportunities for Sanitation Service}

Over the last decade, Ethiopia has made important improvements in expanding access to sanitation. According to the WHO/UNICEF JMP report [14] that being achieved several greatest important improvements towards sanitation coverage, sanitation increased to 71 percent in 2015 just 25 years later from a mere 8 percent coverage in 1990. In Ethiopia, 44.3 million people were practicing open defecation in 1990 and this number has decreased to 28.3 million people after 25 years in 2015. This important success was largely facilitated through its adoption of a Community-led Total Sanitation and Hygiene approach (CLTSH) through the Ethiopian government, which its framework officially implemented in 2011 and enforced throughout the country under the health extension program. Throughout the process of building the policy, carrying out training, and implementing CLTSH across Ethiopia UNICEF has sponsored the MoH. Throughout the year 2000, Community-Led Total Sanitation (CLTS) originated as a participatory solution to tackling open defecation.

Health Extension Workers (HEWs) campaign to introduce CLTS in Ethiopia, where open defecation has been reduced substantially since CLTS was adopted [97]. Besides, Ethiopia is among the least economically developed nations and has been the beneficiary of substantial donor funding to support the Ethiopian government in meeting SDGs. Due to this, there are many development part- 
ners, which have a role in increasing the improved sanitation facility of households in the country. The One WASH national program is the Ethiopian government's key mechanism for achieving the sanitation and hygiene targets in the country's GTP. The country has started also waste treatment and management strategies for both liquid and solid wastes generated from the inhabitants to tackle the sanitation problem, especially in cities. Currently, the government of Ethiopia invests huge amounts of money in water infrastructure to solve the socio-economic problems of the population. The establishment of a hydraulic infrastructure platform to store and disseminate the construction and management of water and urban infrastructure also hopefully solves the current problem. Water infrastructure investment creates greater economic benefits by spending to directly affected businesses and their workers and this can, in turn, improve the current low coverage of sanitation.

\section{Strategies for Achieving Success in Sanitation}

From the studies available three major strategies will be applied in Ethiopia to meet the sanitation target [76]. The most important of such approaches is political leadership, demonstrated in establishing strong administrative accountability with resource allocation for sanitation, and in guaranteeing that government sector agencies operate together in the areas of health, water management, environmental protection, and urban municipal offices. Unfortunately, the government in Ethiopia is neglecting the sanitation sector. As we have mentioned above in Ethiopia the sanitation and waste treatment and management authority are given to the ministry of water irrigation and electricity, the ministry of health (environmental sanitation as well as national hygiene), the ministry of urban development and housing construction, and ministry of environment and forestry.

Efforts to meet the SDG 6.2 goal should emphasize more on enhancing current sanitation systems and sustaining them. To overcome the problems of improving access to sanitation, it is essential for the major stakeholders in Ethiopia's sanitation sector, such as policymakers, health and water sectors, development partners including the population should work together. Formulating clear policies, regulations, strategies, or guidelines for promoting waste collection, transportation, reuse, and recycling is very essential. The policy, therefore, must build demand services, promote and strengthen collaborations between the private sector, Non-Governmental Organizations (NGOs), community-based organizations, local authorities, and individuals and eliminate barriers to improved sanitation. The present level of the funding system for sanitation in Ethiopia is not adequate to meet the SDG goals for sanitation.

The political leadership expresses itself by establishing strong institutional accountability and precise sanitation resource allocation and ensuring that agencies in the public sector can work well together on health, water supplies, and utility services. Awareness creation and empowerment of citizens, particularly 
women's is essential to tackle the current overwhelming problem. Empowerment is indeed a crucial step toward a harmony of regulation and the responsibility to improve sanitation. Improved sanitation infrastructure is largely the responsibility of individual homeowners, except for the centralized sewage system, which is a public and private responsibility. Sanitation should be gender-sensitive and the sanitation policy must serve the interests, priorities, and lifestyles of girls, women, and men in equal proportions.

A Sustainable sanitation approach is needed to tackle the multilateral problems. Initiatives to enhance water quality and sanitation should include policies that take into consideration the impact of increased flows of urban wastewater and downstream agricultural and domestic uses. Measures to control pollution are important to minimize further degradation of particularly heavy metals in water, soils, and crops. A sanitation challenge approach is connected with establishing equity, preserving the consumer, and the general public about the environment. The goal is to build a system that is socially, economically, and environmentally sustainable. The sanitation system would not, however, pollute the atmosphere, nor would it deplete scarce resources. The waste generated from the public and private discharging and treatment mechanisms has to be designed to eliminate and avoid water pollution and related environmental contaminations. This means that sanitation mechanisms do not contribute to the deterioration of water or soil.

\section{Conclusions}

This paper explores the challenges and opportunities of sanitation facilities in Ethiopia. The review also shows the global situation, including Africa to easily compare and narrate Ethiopia's achievement. Even though Ethiopia had substantial progress in improving sanitation facilities in the past decades, currently it has low coverage and most of the people are living with unimproved sanitation. It is essential to know the situation of the country and the problem of unsafe sanitation management as well as its related impacts. Wastewater treatment at the household level and on the public should be practiced for the improvement of the existing situation. Urban and rural sanitation professionals are combining strategies to find ways to achieve the SDG for eliminating open defecation. Comprehensive participation of the environment and health sector has a great opportunity to improve sanitation, and a great deal of strength to help achieve the goal. Reliable data availability, accessibility, and data sharing are important to timely evaluating and taking action for the current problems of sanitation, but there are gaps in information and data about what is potentially dangerous in Ethiopia.

Our finding also indicated that disturbing trends were observed in Ethiopia in the achievements of SDG 6, particularly basic sanitation services that have registered in very slow progress. This also indicated that the major challenge remains in Ethiopia and unless significant measures will be undertaken in the next 10 
years of the SDGs plan, the country will not meet the SDGs at the end of 2030. Therefore, governments and policymakers need to proceed in a way to change their approach and prioritize water and sanitation-related development initiatives that currently need significant improvement in the sanitation services that mainly focusing on formulating effective policy and establishing the strong institution, capacity development in terms of preparation and deployment of human capital, sufficient resource allocation, and logistics arrangements.

\section{Acknowledgements}

I would like to express my sincere gratitude to Professor Hongtao Wang that who originated the concept of the paper and conducted part of the analysis and also critically revised the whole paper. Secondly, I would like to thanks the China Ministry of Commerce (MOFCOM) for financial support through a study of my scholarship, UNEP-TONGJI Institute of Environment for Sustainable Development (IESD), and Tongii University, particularly the College of Environmental Science and Engineering, who gave me the golden opportunity to do this paper entitled "Sustainable Development Goals (SDG) Target 6.2 in Ethiopia: Challenges and Opportunities".

\section{Conflicts of Interest}

The author declares no conflicts of interest regarding the publication of this paper.

\section{References}

[1] Mara, D. and Evans, B. (2018) The Sanitation and Hygiene Targets of the Sustainable Development Goals: Scope and Challenges. Journal of Water Sanitation and Hygiene for Development, 8, 1-16. https://doi.org/10.2166/washdev.2017.048

[2] Aga, A. (2016) Sanitation Practice of Slum Communities in Addis Ababa, Ethiopia. Science Journal of Public Health, 4, 297. https://doi.org/10.11648/j.sjph.20160404.15

[3] Abubakar, I.R. (2017) Access to Sanitation Facilities among Nigerian Households: Determinants and Sustainability Implications. Sustainability, 9, 547. https://doi.org/10.3390/su9040547

[4] Dias, C.M., Rosa, L.P., Gomez, J. and D’Avignon, A. (2018) Achieving the Sustainable Development Goal 06 in Brazil: The Universal Access to Sanitation as a Possible Mission. Anais da Academia Brasileira de Ciências, 90, 1337-1367. https://doi.org/10.1590/0001-3765201820170590

[5] Weststrate, J., Dijkstra, G., Eshuis, J., Gianoli, A. and Rusca, M. (2018) The Sustainable Development Goal on Water and Sanitation: Learning from the Millennium Development Goals. Social Indicators Research, 143, 795-810. https://doi.org/10.1007/s11205-018-1965-5

[6] Hyun, C., et al. (2019) Sanitation for Low-Income Regions: A Cross-Disciplinary Review. Annual Review of Environment and Resources, 44, 287-318. https://doi.org/10.1146/annurev-environ-101718-033327

[7] Baum, R., Luh, J. and Bartram, J. (2013) Sanitation: A Global Estimate of Sewerage Connections without Treatment and the Resulting Impact on MDG Progress. En- 
vironmental Science \& Technology, 47, 1994-2000.

https://doi.org/10.1021/es304284f

[8] Jung, S., et al. (2016) The Effects of Improved Sanitation on Diarrheal Prevalence, Incidence, and Duration in Children under Five in the SNNPR State, Ethiopia: Study Protocol for a Randomized Controlled Trial. Trials, 17, 204.

https://doi.org/10.1186/s13063-016-1319-Z

[9] Schmidt-Traub, G., Kroll, C., Teksoz, K., Durand-Delacre, D. and Sachs, J.D. (2017) National Baselines for the Sustainable Development Goals Assessed in the SDG Index and Dashboards. Nature Geoscience, 10, 547-555. https://doi.org/10.1038/ngeo2985

[10] Khan, S.M., et al. (2017) Optimizing Household Survey Methods to Monitor the Sustainable Development Goals Targets 6.1 and 6.2 on Drinking Water, Sanitation and Hygiene: A Mixed-Methods Field-Test in Belize. PLoS ONE, 12, e0189089. https://doi.org/10.1371/journal.pone.0189089

[11] Yohannes, T., Workicho, A. and Asefa, H. (2014) Cross-Sectional Study: Availability of Improved Sanitation Facilities and Associated Factors among Rural Communities in Lemo Woreda, Hadiya Zone, Southern Ethiopia. Open Access Library Journal, 1, e1020. https://doi.org/10.4236/oalib.1101020

[12] Nansubuga, I., Banadda, N., Verstraete, W. and Rabaey, K. (2016) A Review of Sustainable Sanitation Systems in Africa. Reviews in Environmental Science and Biol Technology, 15, 465-478. https://doi.org/10.1007/s11157-016-9400-3

[13] Odagiri, M., et al. (2020) Achieving the Sustainable Development Goals for Water and Sanitation in Indonesia-Results from a Five-Year (2013-2017) Large-Scale Effectiveness Evaluation. International Journal of Hygiene and Environmental Health, 230, Article ID: 113584. https://doi.org/10.1016/j.ijheh.2020.113584

[14] World Health Organization (2015) WHO/UNICEF Joint Monitoring Programme for Water Supply and Sanitation, Progress on Sanitation and Drinking Water: 2015 Update and MDG Assessment.

[15] Daudey, L. (2018) The Cost of Urban Sanitation Solutions: A Literature Review. Journal of Water, Sanitation and Hygiene for Development, 8, 176-195. https://doi.org/10.2166/washdev.2017.058

[16] Libby, J.A., Wells, E.C. and Mihelcic, J.R. (2020) Moving Up the Sanitation Ladder While Considering Function: An Assessment of Indigenous Communities, Pit Latrine Users, and Their Perceptions of Resource Recovery Sanitation Technology in Panama. Environmental Science \& Technology, 54, 15405-15413. https://doi.org/10.1021/acs.est.0c04120

[17] Seymour, Z. and Hughes, J. (2014) Sanitation in Developing Countries: A Systematic Review of User Preferences and Motivations. Journal of Water, Sanitation and Hygiene for Development, 4, 681-691. https://doi.org/10.2166/washdev.2014.127

[18] Li, X., Hu, Q., Miao, Y., Chen, W. and Yuan, C. (2015) Household Access to Sanitation Facilities in Rural China. Journal of Water, Sanitation and Hygiene for Development, 5, 465-473. https://doi.org/10.2166/washdev.2015.141

[19] Dwipayanti, N.M.U., Phung, T.D., Rutherford, S. and Chu, C. (2017) Towards Sustained Sanitation Services: A Review of Existing Frameworks and an Alternative Framework Combining Ecological and Sanitation Life Stage Approach. Journal of Water, Sanitation and Hygiene for Development, 7, 25-42. https://doi.org/10.2166/washdev.2017.086

[20] Garn, J.V., et al. (2017) The Impact of Sanitation Interventions on Latrine Coverage and Latrine Use: A Systematic Review and Meta-Analysis. International Journal of 
Hygiene and Environmental Health, 220, 329-340.

https://doi.org/10.1016/j.ijheh.2016.10.001

[21] Kaminsky, J.A. and Javernick-Will, A.N. (2014) The Internal Social Sustainability of Sanitation Infrastructure. Environmental Science \& Technology, 48, 10028-10035. https://doi.org/10.1021/es501608p

[22] Templeton, M.R. (2015) Pitfalls and Progress: A Perspective on Achieving Sustainable Sanitation for All. Environmental Science: Water Research \& Technology, 1, 17-21. https://doi.org/10.1039/C4EW00087K

[23] World Health Organization (2008) WHO/UNICEF Joint Monitoring Programme for Water Supply and Sanitation, Progress on Drinking Water and Sanitation: Special Focus on Sanitation.

[24] Dreibelbis, R., et al. (2015) Development of a Multidimensional Scale to Assess Attitudinal Determinants of Sanitation Uptake and Use. Environmental Science \& Technology, 49, 13613-13621. https://doi.org/10.1021/acs.est.5b02985

[25] World Health Organization (2017) WHO/UNICEF Joint Monitoring Programme for Water Supply and Sanitation, Progress on Drinking Water, Sanitation and Hygiene Update and SDG Baselines 2017. Geneva.

[26] United Nations (2018) Water, Sustainable Development Goal 6 Synthesis Report on Water and Sanitation. United Nations New York.

[27] Hopewell, M.R. and Graham, J.P. (2014) Trends in Access to Water Supply and Sanitation in 31 Major Sub-Saharan African Cities: An Analysis of DHS Data from 2000 to 2012. BMC Public Health, 14, 208. https://doi.org/10.1186/1471-2458-14-208

[28] Sclar, G.D., et al. (2016) Assessing the Impact of Sanitation on Indicators of Fecal Exposure along Principal Transmission Pathways: A Systematic Review. International Journal of Hygiene and Environmental Health, 219, 709-723. https://doi.org/10.1016/j.ijheh.2016.09.021

[29] Appiah-Effah, E., Duku, G.A., Azangbego, N.Y., Aggrey, R.K.A., Gyapong-Korsah, B. and Nyarko, K.B. (2019) Ghana's Post-MDGs Sanitation Situation: An Overview. Journal of Water, Sanitation and Hygiene for Development, 9, 397-415. https://doi.org/10.2166/washdev.2019.031

[30] Hutton, G. and Chase, C. (2016) The Knowledge Base for Achieving the Sustainable Development Goal Targets on Water Supply, Sanitation and Hygiene. International Journal of Environmental Research and Public Health, 13, 536. https://doi.org/10.3390/ijerph13060536

[31] Nhamo, G., Nhemachena, C. and Nhamo, S. (2019) Is 2030 Too Soon for Africa to Achieve the Water and Sanitation Sustainable Development Goal? Science of the Total Environment, 669, 129-139. https://doi.org/10.1016/j.scitotenv.2019.03.109

[32] Jones, O. (2015) Monitoring Sanitation and Hygiene in Rural Ethiopia: A Diagnostic Analysis of Systems, Tools and Capacity. The World Bank-Water and Sanitation Program, Africa.

[33] Gebremariam, B., Hagos, G. and Abay, M. (2018) Assessment of Community-Led Total Sanitation and Hygiene Approach on the Improvement of Latrine Utilization in Laelay Maichew District, North Ethiopia. A Comparative Cross-Sectional Study. PLoS ONE, 13, e0203458. https://doi.org/10.1371/journal.pone.0203458

[34] UN Data Booklet (2019) United Nations Department for Economic and Social Affairs, World Population Prospects 2019.

[35] Degu, A.A. (2019) The Nexus between Population and Economic Growth in Ethi- 
opia: An Empirical Inquiry. International Journal of Business and Economic Sciences Applied Research, 12, 43-50. https://doi.org/10.25103/ijbesar.123.05

[36] United Nations, Ethiopia (2018) Ethiopia's Progress towards Eradicating Poverty. Implementation of the Third United Nations Decade for the Eradication of Poverty (2018-2027) Discussion Paper.

[37] Ayalew, D. (2018) Theoretical and Empirical Review of Ethiopian Water Resource Potentials, Challenges and Future Development Opportunities. International Journal of Waste Resources, 8, 353.

[38] Mensah, J. and Ricart Casadevall, S. (2019) Sustainable Development: Meaning, History, Principles, Pillars, and Implications for Human Action: Literature Review. Cogent Social Sciences, 5, Article ID: 1653531. https://doi.org/10.1080/23311886.2019.1653531

[39] FDRE (2017) The 2017 Voluntary National Reviews on SDGs of Ethiopia: Government Commitments, National Ownership and Performance Trends. National Plan Commission, Addis Ababa.

[40] Sachs, J., Schmidt-Traub, G., Kroll, C., Lafortune, G. and Fuller, G. (2019) Sustainable Development Report 2019. Transformations to Achieve the Sustainable Development Goals. Bertelsmann Stiftung. Sustainable Development Solutions Network (SDSN), New York. https://www.sdgindex.org

[41] World Health Organization (2010) WHO/UNICEF Joint Monitoring Programme for Water Supply and Sanitation, Progress on Sanitation and Drinking-Water: 2010 Update. 60.

[42] World Health Organization (2013) WHO/UNICEF Joint Monitoring Programme for Water Supply and Sanitation, Progress on Sanitation and Drinking Water 2013 Update.

[43] World Health Organization (2014) WHO/UNICEF Joint Monitoring Programme for Water Supply and Sanitation, Progress on Drinking Water and Sanitation: 2014 Update.

[44] Beyene, A., Hailu, T., Faris, K. and Kloos, H. (2015) Current State and Trends of Access to Sanitation in Ethiopia and the Need to Revise Indicators to Monitor Progress in the Post-2015 Era. BMC Public Health, 15, 451.

https://doi.org/10.1186/s12889-015-1804-4

[45] Central Statistical Agency (2001) EDHS/CSA, Ethiopia Demographic and Health Survey 2000.

[46] Macro, O. (2006) Ethiopia Demographic and Health Survey 2005. Central Statistical Agency, Addis Ababa.

[47] EDHS/CSA (2012) Ethiopia Democratic Health Survey 2011. Central Statistical Agency, Addis Ababa, Ethiopia ICF International, Calverton.

[48] EDHS/CSA (2012) Ethiopia Demographic and Health Survey, 2016. ICF International, Central Statistical Agency, July 2017.

[49] Adank, M., Butterworth, J., Godfrey, S. and Abera, M. (2016) Looking beyond Headline Indicators: Water and Sanitation Services in Small Towns in Ethiopia. Journal of Water, Sanitation and Hygiene for Development, 6, 435-446. https://doi.org/10.2166/washdev.2016.034

[50] Pullan, R.L., Freeman, M.C., Gething, P.W. and Brooker, S.J. (2014) Geographical Inequalities in the Use of Improved Drinking Water Supply and Sanitation across Sub-Saharan Africa: Mapping and Spatial Analysis of Cross-Sectional Survey Data. PLOS Medicine, 11, e1001626. https://doi.org/10.1371/journal.pmed.1001626 
[51] Shukla, R. (2018) Spatial Disparity in Sanitation Facility: An Empirical Analysis. Journal of Infrastructure Development, 10, 80-95. https://doi.org/10.1177/0974930618812965

[52] Luh, J., Baum, R. and Bartram, J. (2013) Equity in Water and Sanitation: Developing an Index to Measure Progressive Realization of the Human Right. International Journal of Hygiene and Environmental Health, 216, 662-671. https://doi.org/10.1016/j.ijheh.2012.12.007

[53] UNICEF (2017) Progress on CLTSH in Ethiopia: Findings from a National Review. WASH Field Note/FN/01/2017.

[54] Connor, R. (2015) The United Nations World Water Development Report 2015: Water for a Sustainable World. UNESCO Publishing, Paris.

[55] Mosisa, M., Mesele, A., Bogale, B. and Work, K. (2019) Sanitation in Borena Pastoral Community of Ethiopia: Pinpointing the Status and Challenges. Ethiopian Journal of Science and Sustainable Development, 6, 31-37.

[56] Agide, F.D., et al. (2019) Application of Kingdon and Hall Models to Review Environmental Sanitation and Health Promotion Policy in Ethiopia: A Professional Perspective as a Review. Ethiopian Journal of Health Sciences, 29, 277-286.

[57] Beyene, A., Addis, T., Hailu, T., Tesfahun, E., Wolde, M. and Faris, K. (2015) Situational Analysis of Access to Improved Sanitation in the Capital of Ethiopia and the Urgency of Adopting an Integrated Fecal Sludge Management (FSM) System. Science, 3, 726-732. https://doi.org/10.11648/j.sjph.20150305.29

[58] Mekonnen, F.H. (2012) Liquid Waste Management: The Case of Bahir Dar, Ethiopia. Ethiopian Journal of Health Development, 26, 49-53.

[59] Kacprzak, M., et al. (2017) Sewage Sludge Disposal Strategies for Sustainable Development. Environmental Research, 156, 39-46. https://doi.org/10.1016/j.envres.2017.03.010

[60] Gebregiorgs, M.T. (2018) Towards Sustainable Waste Management through the Cautious Design of Environmental Taxes: The Case of Ethiopia. Sustainability, 10, 3088. https://doi.org/10.3390/su10093088

[61] Malik, O.A., Hsu, A., Johnson, L.A. and de Sherbinin, A. (2015) A Global Indicator of Wastewater Treatment to Inform the Sustainable Development Goals (SDGs). Environmental Science \& Policy, 48, 172-185. https://doi.org/10.1016/j.envsci.2015.01.005

[62] Odey, E.A., Li, Z., Zhou, X. and Kalakodio, L. (2017) Fecal Sludge Management in Developing Urban Centers: A Review on the Collection, Treatment, and Composting. Environmental Science and Pollution Research, 24, 23441-23452. https://doi.org/10.1007/s11356-017-0151-7

[63] Orner, K.D. and Mihelcic, J.R. (2018) A Review of Sanitation Technologies to Achieve Multiple Sustainable Development Goals That Promote Resource Recovery. Environmental Science: Water Research \& Technology, 4, 16-32. https://doi.org/10.1039/C7EW00195A

[64] Assefa, Y.T., Babel, M.S., Sušnik, J. and Shinde, V.R. (2019) Development of a Generic Domestic Water Security Index, and Its Application in Addis Ababa, Ethiopia. Water, 11, 37. https://doi.org/10.3390/w11010037

[65] Van Rooijen, D. and Taddesse, G. (2009) Urban Sanitation and Wastewater Treatment in Addis Ababa in the Awash Basin, Ethiopia. Proceedings of the 34 th WEDC International Conference, Addis Ababa, 18-22 May 2009, 18-22.

[66] Aiemjoy, K., et al. (2017) Is Using a Latrine "A Strange Thing to Do"? A Mixed- 
Methods Study of Sanitation Preference and Behaviors in Rural Ethiopia. The American Society of Tropical Medicine and Hygiene, 96, 65-73. https://doi.org/10.4269/ajtmh.16-0541

[67] Fry, L.M., Mihelcic, J.R. and Watkins, D.W. (2008) Water and Nonwater-Related Challenges of Achieving Global Sanitation Coverage. Environmental Science \& Technology, 42, 4298-4304. https://doi.org/10.1021/es7025856

[68] World Vision Ethiopia/UNICEF (2016) Ethiopia's One, WASH National Programme. The Open University UK.

[69] Kumie, A. and Ali, A. (2005) An Overview of Environmental Health Status in Ethiopia with Particular Emphasis to Its Organization, Drinking Water and Sanitation: A Literature Survey. Ethiopian Journal of Health Development, 19, 89. https://doi.org/10.4314/ejhd.v19i2.9977

[70] I. U. JSI John Snow (2015) Situational Analysis of Urban Sanitation and Waste Management in Ethiopia: The Structural, Socio-Economic, Institutional, Organizational, Environmental, Behavioral, Cultural, Socio-Demographic Dimensions.

[71] Terefe, B. and Welle, K. (2008) Policy and Institutional Factors Affecting Formulation and Implementation of Sanitation and Hygiene Strategy. A Case Study from the Southern Nations Region (SNNPR) of Ethiopia. RiPPLE, Addis Ababa, 42.

[72] Welle, K. (2014) Monitoring Performance or Performing Monitoring? Exploring the Power and Political Dynamics Underlying Monitoring the MDG for Rural Water in Ethiopia. Canadian Journal of Development Studies, 35, 155-169. https://doi.org/10.1080/02255189.2014.877380

[73] UNICEF/WSP (2015) Water Supply and Sanitation in Ethiopia; Turning Finance into Services for 2015 and Beyond. An AMCOW Country Status Overview.

[74] Bartram, J., Brocklehurst, C., Bradley, D., Muller, M. and Evans, B. (2018) Policy Review of the Means of Implementation Targets and Indicators for the Sustainable Development Goal for Water and Sanitation. NPJ Clean Water, 1, 1-5. https://doi.org/10.1038/s41545-018-0003-0

[75] Nagy, J.A., Benedek, J. and Ivan, K. (2018) Measuring Sustainable Development Goals at a Local Level: A Case of a Metropolitan Area in Romania. Sustainability, 10, 3962. https://doi.org/10.3390/su10113962

[76] Mara, D., Lane, J., Scott, B. and Trouba, D. (2010) Sanitation and Health. PLOS Medicine, 7, e1000363. https://doi.org/10.1371/journal.pmed.1000363

[77] Mekonnen, M.M. and Hoekstra, A.Y. (2016) Four Billion People Facing Severe Water Scarcity. Science Advances, 2, e1500323. https://doi.org/10.1126/sciadv.1500323

[78] Van Minh, H. and Nguyen-Viet, H. (2011) Economic Aspects of Sanitation in Developing Countries. Environ Health Insights, 5, 63-70. https://doi.org/10.4137/EHI.S8199

[79] World Bank (2017) Reducing Inequalities in Water Supply, Sanitation, and Hygiene in the Era of the Sustainable Development Goals: Synthesis Report of the Wash Poverty Diagnostic Initiative. WASH Synthesis Report.

[80] Rouse, M. (2014) The Worldwide Urban Water and Wastewater Infrastructure Challenge. International Journal of Water Resources Development, 30, 20-27. https://doi.org/10.1080/07900627.2014.882203

[81] Medland, L.S., Scott, R.E. and Cotton, A.P. (2016) Achieving Sustainable Sanitation Chains through Better Informed and More Systematic Improvements: Lessons from Multi-City Research in Sub-Saharan Africa. Environmental Science: Water Research \& Technology, 2, 492-501. https://doi.org/10.1039/C5EW00255A 
[82] Andersson, K., Dickin, S. and Rosemarin, A. (2016) Towards "Sustainable" Sanitation: Challenges and Opportunities in Urban Areas. Sustainability, 8, 1289. https://doi.org/10.3390/su8121289

[83] Tilley, E., et al. (2014) Looking beyond Technology: An Integrated Approach to Water, Sanitation, and Hygiene in Low-Income Countries. ACS Publications. https://doi.org/10.1021/es501645d

[84] Novotny, J., Hasman, J. and Lepic, M. (2018) Contextual Factors and Motivations Affecting Rural Community Sanitation in Low- and Middle-Income Countries: A Systematic Review. International Journal of Hygiene and Environmental Health, 221, 121-133. https://doi.org/10.1016/j.ijheh.2017.10.018

[85] Exley, J.L., Liseka, B., Cumming, O. and Ensink, J.H.J. (2015) The Sanitation Ladder, What Constitutes an Improved Form of Sanitation? Environmental Science \& Technology, 49, 1086-1094. https://doi.org/10.1021/es503945x

[86] Dugassa Girsha, W. (2016) Assessment of Water, Sanitation and Hygiene Status of Households in Welenchiti Town, Boset Woreda, East Shoa Zone, Ethiopia. Science Journal of Public Health, 4, 435. https://doi.org/10.11648/j.sjph.20160406.13

[87] Tessema, R.A. (2017) Assessment of the Implementation of Community-Led Total Sanitation, Hygiene, and Associated Factors in Diretiyara District, Eastern Ethiopia. PLoS ONE, 12, e0175233. https://doi.org/10.1371/journal.pone.0175233

[88] Alemu, F., Kumie, A., Medhin, G., Gebre, T. and Godfrey, P. (2017) A Socio-Ecological Analysis of Barriers to the Adoption, Sustainability and Consistent Use of Sanitation Facilities in Rural Ethiopia. BMC Public Health, 17, Article No. 706. https://doi.org/10.1186/s12889-017-4717-6

[89] Seyoum, S. and Graham, J.P. (2016) Equity in Access to Water Supply and Sanitation in Ethiopia: An Analysis of EDHS Data (2000-2011). Journal of Water, Sanitation and Hygiene for Development, 6, 320-330. https://doi.org/10.2166/washdev.2016.004

[90] Adane, M., Mengistie, B., Kloos, H., Medhin, G. and Mulat, W. (2017) Sanitation Facilities, Hygienic Conditions, and Prevalence of Acute Diarrhea among Under-Five Children in Slums of Addis Ababa, Ethiopia: Baseline Survey of a Longitudinal Study. PLoS ONE, 12, e0182783. https://doi.org/10.1371/journal.pone.0182783

[91] Tadesse, B., Worku, A., Kumie, A. and Yimer, S.A. (2017) Effect of Water, Sanitation, and Hygiene Interventions on Active Trachoma in North and South Wollo Zones of Amhara Region, Ethiopia: A Quasi-Experimental Study. PLOS Neglected Tropical Diseases, 11, e0006080. https://doi.org/10.1371/journal.pntd.0006080

[92] Grimes, J.E., et al. (2016) School Water, Sanitation, and Hygiene, Soil-Transmitted Helminths, and Schistosomes: National Mapping in Ethiopia. PLOS Neglected Tropical Diseases, 10, e0004515. https://doi.org/10.1371/journal.pntd.0004515

[93] Ige, S. and Adetunji, A. (2014) On Some Socio-Economic Factors Affecting Household Sanitation in Ado-Ekiti, Ekiti State, Nigeria. Journal of Environmental \& Earth Sciences, 4, 35-41.

[94] Vidal, B., Hedström, A., Barraud, S., Kärrman, E. and Herrmann, I. (2019) Assessing the Sustainability of On-Site Sanitation Systems Using Multi-Criteria Analysis. Environmental Science: Water Research \& Technology, 5, 1599-1615. https://doi.org/10.1039/C9EW00425D

[95] Chaudhuri, S. and Roy, M. (2017) Rural-Urban Spatial Inequality in Water and Sanitation Facilities in India: A Cross-Sectional Study from Household to National Level. Applied Geography, 85, 27-38. https://doi.org/10.1016/j.apgeog.2017.05.003 
[96] Prasetyoputra, P. and Irianti, S. (2013) Access to Improved Sanitation Facilities in Indonesia: An Econometric Analysis of Geographical and Socioeconomic Disparities. Journal of Applied Sciences in Environmental Sanitation, 8, 215-224.

[97] Crocker, J., Geremew, A., Atalie, F., Yetie, M. and Bartram, J. (2016) Teachers and Sanitation Promotion: An Assessment of Community-Led Total Sanitation in Ethiopia. Environmental Science \& Technology, 50, 6517-6525.

https://doi.org/10.1021/acs.est.6b01021 